[11] Dalal, S., Nicolle, L., Marrs, C. F., Zhang, L., Harding, G., Foxman, B. (2009). Long-TermEscherichia coliAsymptomatic Bacteriuria among Women with Diabetes Mellitus. Clinical Infectious Diseases, 49 (4), 491-497. doi: 10.1086/600883

[12] Oktar, S. Ö., Yücel, C., Özdemir, H., Karaosmanoglu, D. (2004). Doppler Sonography of Renal Obstruction. Journal of Ultrasound in Medicine, 23 (7), 929-936. doi: 10.7863/jum.2004.23.7.929

[13] Geerlings, S. E. (2008). Urinary tract infections in patients with diabetes mellitus: epidemiology, pathogenesis and treatment. International Journal of Antimicrobial Agents, 31, 54-57. doi: 10.1016/ j.ijantimicag.2007.07.042

[14] Kokrdová, Z., Pařízek, A., Koucký, M., Pašková, A., Boudová, B. (2016). Septic shock in pregnancy on the basis of an acute pyelonephritis. Ceska Gynekol, 81 (4), 286-288.

[15] Matuszkiewicz-Rowińska, J., Małyszko, J., Wieliczko, M. (2015). State of the art paper Urinary tract infections in pregnancy: old and new unresolved diagnostic and therapeutic problems. Archives of Medical Science, 1, 67-77. doi: 10.5114/aoms.2013.39202

[16] Jepson, R. G., Williams, G., Craig, J. C. (2012). Cranberries for preventing urinary tract infections. Cochrane Database of Systematic Reviews. doi: 10.1002/14651858.cd001321.pub5

[17] Pazos Otero, N., Fuentes Ricoy, L., Ferrández Pérez, B., Martínez Vázquez, C., Martínez Poch, M., Osuna Díaz, J. L. (2007). Pyelonephritis and pregnancy. Our experience in a general hospital. Anales de Medicina Interna, 24 (12), 585-587.

[18] Sheiner, E., Mazor-Drey, E., Levy, A. (2009). Asymptomatic bacteriuria during pregnancy. The Journal of Maternal-Fetal \& Neonatal Medicine, 22 (5), 423-427. doi: 10.1080/14767050802360783

[19] Smaill, F. M., Vazquez, J. C. (2015). Antibiotics for asymptomatic bacteriuria in pregnancy. Cochrane Database of Systematic Reviews. doi: 10.1002/14651858.cd000490.pub3

[20] Ailomazyan, E. K. (1999). Obstetrics. Saint-Petersburg, 850.

\title{
INVESTIGATION OF THE CHEMICAL COMPOSITION AND EFFICIENCY OF SEED OIL OF SPINDLE TREE (EUONYMUS EUROPAEA L.) ON THE MODEL OF NON-ALLERGIC DERMATITIS
}

\author{
Olha Vrubel \\ Department of Pharmacognosy and Botany \\ Danylo Halysky Lviv National Medical University \\ 69 Pekarska str., Lviv, Ukraine, 79010 \\ Igor Nektegaev \\ Department of Pharmacology \\ Danylo Halysky Lviv National Medical University \\ 69 Pekarska str., Lviv, Ukraine, 79010 \\ Volodymyr Antonyuk \\ Department of Pharmceutical chemistry and pharmacognosyFPGE \\ Danylo Halysky Lviv National Medical University \\ 69 Pekarska str., Lviv, Ukraine 79010 \\ Institute of Cell Biology of National Academy of Sciences of Ukraine \\ 14/16 Dragomanova str., Lviv, Ukraine, 79005
}

Abstract

The aim of the research was to study the chemical composition and effectiveness of the seed oil of Spindle tree (Euonymus europaea L.) on the non-allergic contact dermatitis model. 
The oil was obtained by the extraction by petroleum ether from the seeds. The analysis of fatty acids and determination of their quantitative content was carried out using gas chromatography. Determination of carotenoids and tocopherols content in fatty oils was carried out after chromatography on a silica gel column. Investigation of anti-inflammatory action of the Spindle tree seed oil on white rats was carried. Determination of biochemical parameters of blood plasma was performed on the semi-automatic biochemical analyzer BS3000M (Poland).

The yield of oil was $20-28 \%$ of the weight of the seeds. Nine fatty acids were identified in the oil by the gas chromatography, among which 4 are unsaturated (oleic, palmitoleic, linoleic and linolenic), which together make up $87.79 \%$ of all fatty acids from this oil. Spindle tree oil contains $26 \pm 5 \mathrm{mg}-\%$ carotenoids and $40 \pm 5 \mathrm{mg}-\%$ tocopherols, which were separated by chromatography on a silica gel column. There were no symptoms of intoxication with the introduction of Spindle tree oil in the stomach of rats and it can be classified in the 4 the grade of danger in accordance with GOST 12.1.005-88.

The anti-inflammatory activity of Spindle tree oil in comparison with the oil of Sea buckthorn on the model of non-allergic contact dermatitis was weaker, but sufficient to recommend it for the treatment of skin diseases in ointments.

Keywords: fatty oil, Euonymus europaea L., fatty acid composition, carotenoids, tocopherols, dermatitis.

\section{Introduction}

Contact dermatitis is an inflammatory reaction of the skin in response to the effects of various chemical stimuli. There are simple (non-allergic) and allergic dermatitis. Contact non-allergic dermatitis, unlike allergic, occurs exclusively in the place of exposure of the irritant. A compulsory component of complex treatment of contact dermatitis is local therapy. Very often, various ointments containing steroidal anti-inflammatory drugs, which have a number of restrictions for patients with hypersensitivity, for the elderly, children, pregnant women and lactating women, are used for this purpose. An alternative to synthetic anti-inflammatory agents is phytopreparations that exhibit a mild, complex action $[1,2]$.

Our attention was drawn to the Spindle tree oil (Euonymus europaea L.), which, according to folk medicine, is effective in dermatomycosis and eczema [3-7]. However, data on the effectiveness of this oil in comparison with other dermatological agents and what kind of chemicals this action is stipulated, is not enough.

\section{Aim of the research}

Study the chemical composition and effectiveness of the Spindle tree seed oil on the non-allergic contact dermatitis model.

\section{Materials and methods}

The seeds of Euonymus europaea L. were manually separated from the pericarps, and then they were powdered on an coffee-grinder. The weight of the crushed raw material was poured with petroleum ether $\left(\mathrm{t}_{\text {boil }}=40-70{ }^{\circ} \mathrm{C}\right)$ in the ratio of the seeds: extractant $-1: 5$, and after a 30 minute stirring, the petroleum ether extract was filtered out through a dense cloth. The oilcake was re-poured with petroleum ether and after 30 minutes of stirring, the petroleum ether extract was filtered out through a dense cloth repeatedly and added to the previous extract. The combined extracts were purified by centrifugation (10 $\mathrm{min}$ at $2500 \mathrm{~g}$ ), and after filtering the petroleum ether was distilled off in a water bath, and the residue was dried in a porcelain cup at $+60{ }^{\circ} \mathrm{C}$ in a drying oven overnight.

After of the oil have been obtained it was weighed and the determination of numerical parameters according to the methods of the State Pharmacopeia of Ukraine were performed [8].

The analysis of fatty acids and determination of their quantitative content was carried out using gas chromatography on chromatograph Chrom-5 according to GOST 30418-96 [9, 10].

Determination of carotenoids and tocopherols content in fatty oils was carried out after chromatography on a silica gel column. For this purpose, the exact weight of the fatty oil $(0.870 \mathrm{~g})$ was dissolved in $5.0 \mathrm{ml}$ of chloroform and applied onto a column of silica gel $(\mathrm{h}=25 \mathrm{~cm}, \mathrm{~d}=1.2$ 
$\mathrm{cm})$, pre-rinsed with a mixture of chloroform: acetic acid, 100:1. Fractions were collected in 1.5 $\mathrm{ml}$ into a test tube weighed to $0.001 \mathrm{~g}$. After flowing out of 22 fractions, the column was washed with a mixture of chloroform: acetic acid: methanol: 100:1:4 (the following 23 fractions), and then the eluation was carried out with a mixture of chloroform: acetic acid: methanol: 100:1:150 the following 23 fractions). After washing the column, the solvent evaporated in a desiccator at $+60{ }^{\circ} \mathrm{C}$ and the obtained fractions were weighed and build the diagram of the mass fractions from their numbers (Fig. 1). The obtained fractions were analyzed by TLC for the presence of carotenoids and tocopherols. Detection of carotenoids was carried out by reaction with a $2 \%$ solution of para-aminobenzaldehyde in a mixture of ethanol and hydrochloric acid, followed by chromatogram holding in a desiccator at $90{ }^{\circ} \mathrm{C}[11,12]$. Carotenoids on chromatograms were stained in a pinkish-purple colour.

The detection of tocopherols was carried out after spraying the chromatogram with $56 \%$ nitric acid followed by holding the chromatogram in a desiccator at $80^{\circ} \mathrm{C}$. In the presence of tocopherols, the stains are orange-red in colour, unlike carotenoids and steroids that do not give such a coloring.

Quantitative determination of carotenoids was carried out in combined fractions where they were found by measuring of chloroform solution at $460 \mathrm{~nm}$ on spectrophotometer SF-46 in a cuvette with a layer thickness of $10 \mathrm{~mm}$. For this purpose, fractions No. 9-26 were dissolved in $50 \mathrm{ml}$ of chloroform [13-15]. the formula:

Quantitative content of carotenoids (C, in $\mathrm{mg-} \%$ ) in terms of $\beta$-carotene was calculated by

$$
C=\frac{E_{460} \times 50 \times 100 \times 10}{g \times 2500},
$$

where $\mathrm{E}_{460}$ - optical density of the investigated solution; 50 - dilution in $\mathrm{ml} ; 2500$ - specific absorption rate of $1 \%$ solution of $\beta$-carotene in a cuvette $1.0 \mathrm{~cm}$; $\mathrm{g}$ - weight in $\mathrm{g}$.

Similarly, according to the same formula, the quantity of tocopherols was determined, with the difference that the fractions where the tocopherols were found were dissolved in methanol and the determination was carried out at $281 \mathrm{~nm}$, and, accordingly, in the formula instead of 2500, the values were: 1022 - specific absorption rate of $1 \%$ solution of tocopherol in methanol in a cuvette $1.0 \mathrm{~cm}[16,17]$.

Since there is evidence that a Spindle tree (Euonymus europaea L.) is a poisonous plant (seeds contain cardiac glycosides and alkaloids) [3], for the control of the possibility of their entry into the oil, the determination of acute toxicity was made. For this purpose, rats (Wistar lines) weighing 180-200 g were orally injected with $10 \mathrm{~g} / \mathrm{kg}$ of oil. Observation of animals was carried out for 14 days.

After establishing a practical non-toxicity of the oil during oral administration, it was conducted to investigate its anti-inflammatory action on the model of non-allergic contact dermatitis on 19 white rats weighing $180-200 \mathrm{~g}$.

Experimental animals were divided into 3 groups:

I - Intact control, animals without treatment (IR) $(n=5)$;

II - Animals treated with a comparison substance (Sea buckthorn oil) (n=7);

III - Animals treated with researched oil of Euonymus europaea $(\mathrm{n}=7)$.

The protocol of the study has been approved by been agreed with the Ethics Committee of the Danylo Halysky Lviv National Medical University (the protocol No. 2 dated February 15,2016$)$.

The animals behaved in accordance with the "General ethical principles of animal experiments consistent with the provisions of the "European Convention for the Protection of Vertebrate Animals used for Experimental and Scientific Purposes" (Strasbourg, 1986, as amended in 1998). Council of Europe 2010/63/EU, Law of Ukraine No. 3447-IV “On protection of animals from cruel treatment". 
For reproduction of the pathology to animals on a stripped skin area of $3 \times 3 \mathrm{~cm}^{2}$ in 10 days, 5 drops of turpentine were applied and rubbed with a glass rod. On the 10th day of reproduction of pathology in animals, the intensity of developed non-allergic contact dermatitis was assessed visually for the expressive inflammatory response of the skin by the ball system ( 0 points - no visible reaction, 1 point - weak erythema, 2 points - moderately expressed erythema with peeling and spot hemorrhages; 3 points - clear erythema with seals and flaking; 4 points - sharp erythema with the phenomena of haemorrhage, severe infiltration and serous-hemorrhagic crusts with ulcers) $[2,18]$.

After that, for 10 days, the treated oils were applied to the injured areas of the skin using a sterile spatula and the intensity of the external manifestations of the inflammation process was assessed on the $14^{\text {th }}, 17^{\text {th }}$ and $20^{\text {th }}$ days of the experiment.

The intensity of the inflammatory process in the animal's body was also evaluated by the hematological parameters: erythrocyte sedimentation rate and the amount of white blood cells that were determined on the $10^{\text {th }}$ day of the application of turpentine and on the $5^{\text {th }}$ day of local dermatitis treatment (15 the day of the experiment).

The determination of erythrocyte sedimentation rate (ESR) was carried out using the Westergren method [19]. For this, the venous blood sample was mixed with a $5 \%$ solution of sodium citrate in a ratio of $4: 1$, after which the resulting sample was placed in a standard capillary Vestergrena (capillaries in the length of $300 \pm 1.5 \mathrm{~mm}$ (working length of the capillary $-200 \mathrm{~mm}$ ), diameter $-2,55 \pm 0.15 \mathrm{~mm}$ ). The value of ESR was estimated by the height of the plasma layer in millimetres, which was formed in 1 hour.

To assess the morphology of leukocytes (leukogram), smears of blood were prepared on a object-plate, which were then stained by the Romanovsky-Giemsa dye and microscopically.

Since in the inflammatory process metabolic changes occur in the animal's organism, on the $15^{\text {th }}$ day of the experiment in the blood serum, biochemical parameters that characterize the severity of the inflammatory process (amount of total protein, urea, cytolytic enzyme AsAT and glycoproteins [20] were performed.

Determination of biochemical parameters of blood plasma was performed on the semi-automatic biochemical analyzer BS3000M, SINNOWA, PRC, using standard test systems manufactured by CORMAY, Poland.

The results obtained were statistically processed using the standard statistic package of Statistica 4.3.

\section{Results}

The obtained Spindle tree oil - a viscous liquid of bright orange colour with a specific odour.

The yield of oil is $20-28 \%$ of the weight of the seeds. The main numerical parameters of the fatty oil of the seeds of Spindle tree are presented in Table $\mathbf{1 .}$

Table 1

Numerical parameters of Spindle tree oil

\begin{tabular}{cccccccc}
\hline \multirow{2}{*}{ Extragent } & \multicolumn{5}{c}{ Numerical parameters } \\
\cline { 2 - 8 } & $\begin{array}{c}\text { \% yield from } \\
\text { raw materials }\end{array}$ & $\begin{array}{c}\text { Density } \\
\left(\text { at } \mathbf{2 0} \mathbf{~} \mathbf{C}^{\mathbf{C}} \mathbf{g} / \mathbf{c m}^{3}\right.\end{array}$ & $\begin{array}{c}\text { Refraction } \\
\text { index }\end{array}$ & Acid value & $\begin{array}{c}\text { Saponifi- } \\
\text { cation value }\end{array}$ & Ethericvalue & Iodine value \\
\hline $\begin{array}{c}\text { Petroleum } \\
\text { ether }\end{array}$ & $24 \% \pm 4 \%$ & 0.939 & 1.475 & 4.04 & 149.9 & 145.86 & 120
\end{tabular}

Fatty acids of Spindle tree oil were separated by gas chromatography on Chrom-5 chromatograph. Diagram of separation is presented in Fig. 1. The results of chromatographic separation are presented in Table 2. 


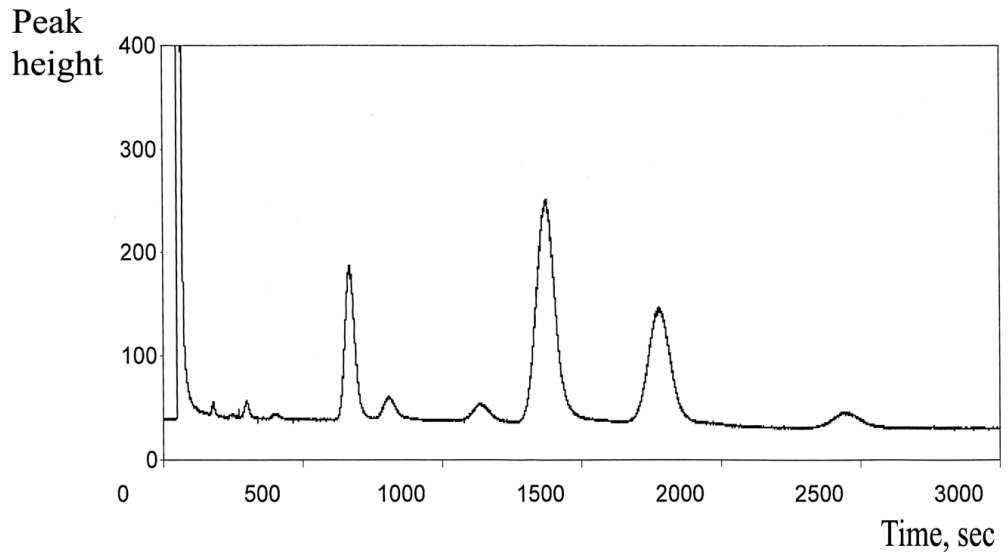

Fig. 1. Chromatogram of the fatty acid profile from a Spindle tree oil: Chromatograph - Chrom-5, sample injecting $-2 \mu 1$

Table 2

Fatty acid composition of Spindle tree oil

\begin{tabular}{ccccccc}
\hline No. & Fatty acid & $\begin{array}{c}\text { Retention time } \\
\text { (sec) RT }\end{array}$ & Peak height & Coefficient & Peak Square & Area (\%) \\
\hline 1 & C 10:0 (Capric acid) & 177.6 & 12.0660 & 0.10 & 1.21 & 0.13 \\
2 & C 12:0 (Lauric acid) & 298.0 & 15.0095 & 0.18 & 2.70 & 0.29 \\
3 & C 14:0 (Myristoleic acid) & 403.0 & 3.8985 & 0.31 & 1.21 & 0.13 \\
4 & C 16:0 (Palmitoleic acid) & 668.1 & 46.7572 & 0.60 & 88.06 & 9.46 \\
5 & C 16:1 (Palmitoleic acid) & 808.4 & 20.31 & 0.87 & 17.68 & 1.90 \\
6 & C 18:0 (Stearic acid) & 1138.6 & 13.9319 & 1.47 & 20.48 & 2.20 \\
7 & C 18:1 (Oleic acid) & 1372.2 & 209.9759 & 2.09 & 438.84 & 47.15 \\
8 & C 18:2 (Linoleic acid) & 1779.6 & 108.0784 & 2.79 & 301.54 & 32.40 \\
9 & C 18:3 (Linolenic acid) & 2445.9 & 13.8875 & 4.25 & 59.03 & 6.34
\end{tabular}

The fatty oils were separated on a silica gel column and the obtained fractions were analyzed using TLC.

The graph of the separation of Spindle tree oil on a silica gel column is presented in Fig. 2.

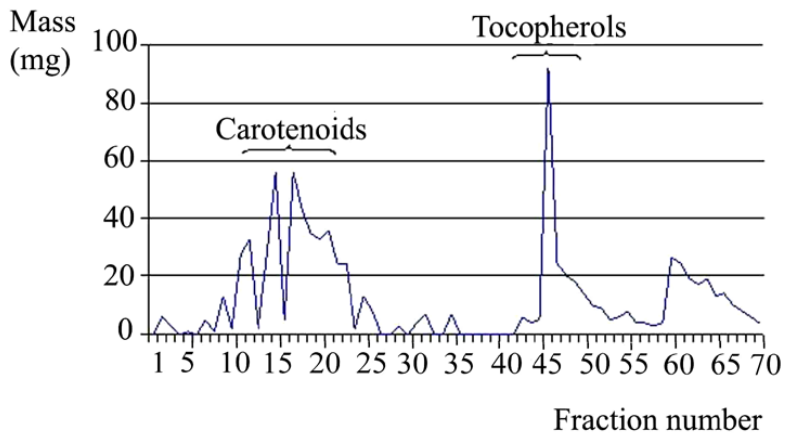

Fig. 2. Separation of carotenoids and tocopherols on a silica gel column

Chromatography on the "Silufol" plates of various fractions obtained by column chromatography showed the presence of carotenoids in 9 to 25 fractions and their absence in other fractions. Tocopherols were found in 45-53 fractions. All fractions (No. 9-64), in addition to 6569 fractions, were reacted with phosphoric-molybdic acid. The solutions of fractions Nos. 9, 10, 12, 20, 21 in isoamyl alcohol gave characteristic spectra for carotenoids (characteristic maximum 
in the region of 450-460 nm), however, they differed slightly, which may indicate differences in their composition. For an example in Fig. 3 shows the UV spectra of fractions No. 9 and No. 20, measured on a NanoDrop 1000 spectrophotometer 3.8.1 (Fig. 3, $\boldsymbol{a}, \boldsymbol{b}$ ).

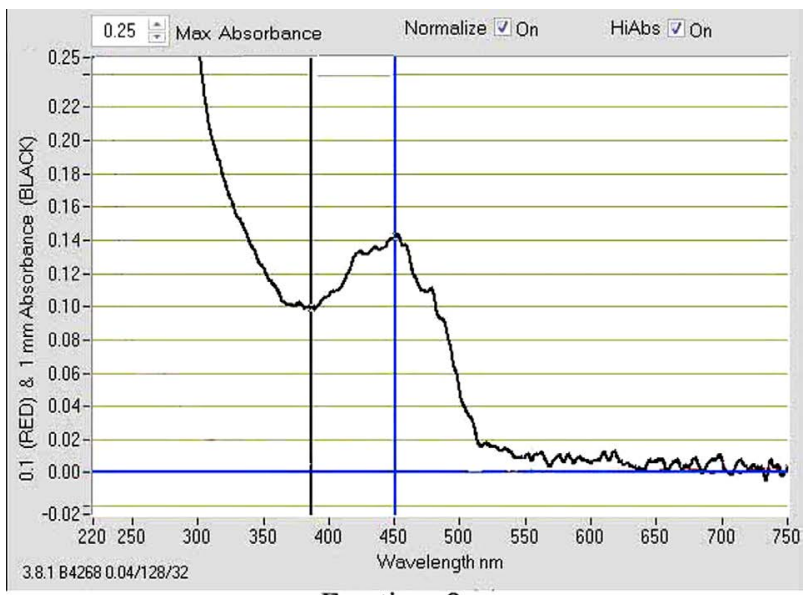

Fraction 9

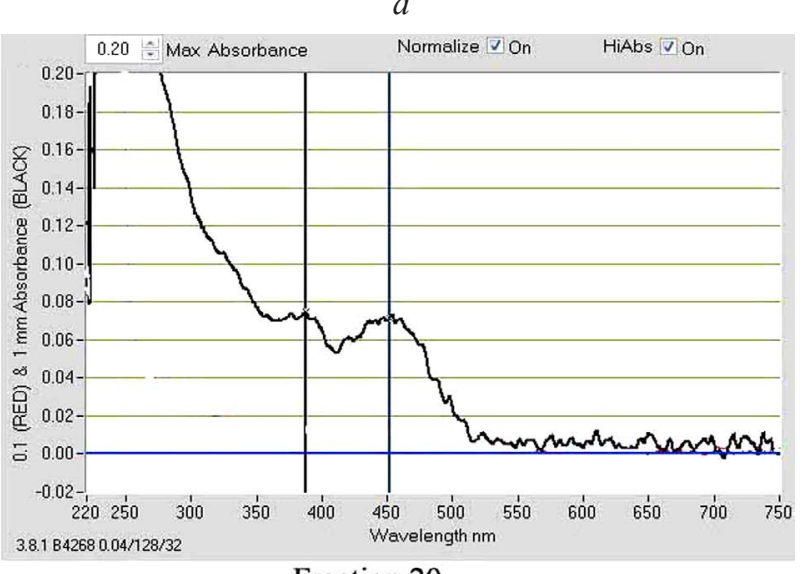

Fraction 20

$b$

Fig. 3. UV spectra of fractions No. $9(a)$ and No. $20(b)$ of Spindle tree (Euonymus europaea L.) oil

It should be noted that all these fractions contained also fatty acids, which constituted the bulk of them, therefore, for the quantitative determination of carotenoids and tocopherols, a spectrophotometric determination method was used.

The results of the visual observation of the anti-inflammatory effect of Spindle tree oil on the non-allergic contact dermatitis model are given in Table 3.

Table 3

Results of visual observation of the anti-inflammatory effect of Spindle tree oil

\begin{tabular}{|c|c|c|c|}
\hline \multirow[b]{2}{*}{ Terms of research (days) } & \multicolumn{3}{|c|}{ Indicators of inflammatory reaction of the skin (in balls according to the intensity of the affection) } \\
\hline & $\begin{array}{c}\text { Intact control, animals } \\
\text { without treatment }\end{array}$ & $\begin{array}{c}\text { Animals treated with } \\
\text { researched oil of Spindle tree }\end{array}$ & $\begin{array}{l}\text { Animals treated with a compari- } \\
\text { son substance (Sea buckthorn oil) }\end{array}$ \\
\hline Output data & - & - & - \\
\hline $10^{\text {th }}$ day of the research & $2.5 \pm 0.5$ & $2.5 \pm 0.5$ & $2.5 \pm 0.5$ \\
\hline $15^{\text {th }}$ day of the & $2.0 \pm 0.5$ & $1.0 \pm 0.5$ & 0 \\
\hline $17^{\text {th }}$ day & $1.0 \pm 0.5$ & 0 & 0 \\
\hline $20^{\text {th }}$ day & 0 & 0 & 0 \\
\hline
\end{tabular}


On the $10^{\text {th }}$ day of application of turpentine in all animals, inflammation of the skin was accompanied by probable control group leukocytosis and elevated ESR (erythrocyte sedimentation rate). Blood test results are shown in Table 4, 5 .

Table 4

The impact of Spindle tree and sea buckthorn oil on hematological parameters in rats on a model of nonallergic contact dermatitis

\begin{tabular}{ccccc}
\hline \multirow{2}{*}{$\begin{array}{c}\text { Terms of research } \\
\text { (days) }\end{array}$} & $\begin{array}{c}\text { Control } \\
\text { (healthy animals) }\end{array}$ & $\begin{array}{c}\text { Intact control, } \\
\text { (animals without } \\
\text { treatment) }\end{array}$ & $\begin{array}{c}\text { Animals treated with } \\
\text { researched oil of } \\
\text { Spindle tree }\end{array}$ & $\begin{array}{c}\text { Animals treated with a } \\
\text { comparison substance } \\
\text { (sea buckthorn oil) }\end{array}$ \\
\cline { 2 - 5 } & & Leukocytes, $10^{9} / 1$ & & $18.36 \pm 1.16$ \\
$10^{\text {th }}$ day of the applica- & $11.42 \pm 1.21$ & $18.36 \pm 1.16$ & $18.36 \pm 1.16$ & $11.75 \pm 0.98$ \\
tion & $12.14 \pm 0.94$ & $15.36 \pm 1.06$ & $14.76 \pm 1.09$ & $3.70 \pm 0.31$ \\
$15^{\text {th }}$ day & $1.45 \pm 0.20$ & ESR, mm/sec & & $1.55 \pm 0.30$ \\
& $1.54 \pm 0.25$ & $3.70 \pm 0.31$ & $3.70 \pm 0.31$ & $2.21 \pm 0.33$
\end{tabular}

Table 5

Effect of Spindle tree (Euonymus europaea L.) oil and sea buckthorn oil on some biochemical indices in rats on the model of non-allergic contact dermatitis

\begin{tabular}{|c|c|c|c|c|}
\hline \multirow[b]{2}{*}{$\begin{array}{l}\text { Terms of research } \\
\text { (days) }\end{array}$} & \multicolumn{4}{|c|}{ Groups of animals } \\
\hline & $\begin{array}{c}\text { Control } \\
\text { (healthy animals) }\end{array}$ & $\begin{array}{l}\text { Intact control, } \\
\text { (animals without } \\
\text { treatment) }\end{array}$ & $\begin{array}{l}\text { Animals treated with } \\
\text { researched oil of } \\
\text { Euonymus europaea } L \text {. }\end{array}$ & $\begin{array}{l}\text { Animals treated with a } \\
\text { comparison substance } \\
\text { (sea buckthorn oil) }\end{array}$ \\
\hline \multicolumn{5}{|c|}{ Total protein $\mathrm{g} / \mathrm{l}$} \\
\hline $10^{\text {th }}$ day & $75.3 \pm 5.6$ & $47.6 \pm 4.9$ & $47.6 \pm 4.9$ & $47.6 \pm 4.9$ \\
\hline $15^{\text {th }}$ day & $72.3 \pm 5.2$ & $58.6 \pm 5.3$ & $61.7 \pm 4.5$ & $70.9 \pm 5.4$ \\
\hline \multicolumn{5}{|c|}{ Urea, mmol/1 } \\
\hline $10^{\text {th }}$ day & $8.72 \pm 0.63$ & $12.65 \pm 0.87$ & $12.65 \pm 0.87$ & $12.65 \pm 0.87$ \\
\hline $15^{\text {th }}$ day & $8.51 \pm 0.56$ & $10.32 \pm 0.61$ & $9.12 \pm 0.57$ & $8.83 \pm 0.65$ \\
\hline \multicolumn{5}{|c|}{ Beta-lipoproteins (LDL-C), mmol/1 } \\
\hline $10^{\text {th }}$ day & $0.98 \pm 0.11$ & $1.53 \pm 0.18$ & $1.53 \pm 0.18$ & $1.53 \pm 0.18$ \\
\hline $15^{\text {th }}$ day & $1.08 \pm 0.13$ & $1.28 \pm 0.16$ & $1.12 \pm 0.13$ & $1.07 \pm 0.16$ \\
\hline \multicolumn{5}{|c|}{ AsAT, IU/1 } \\
\hline $10^{\text {th }}$ day & $0.21 \pm 0.05$ & $0.37 \pm 0.05$ & $0.37 \pm 0.05$ & $0.37 \pm 0.05$ \\
\hline $15^{\text {th }}$ day & $0.22 \pm 0.05$ & $0.30 \pm 0.06$ & $0.28 \pm 0.04$ & $0.23 \pm 0.06$ \\
\hline
\end{tabular}

\section{Discussion}

The vegetable oil can be obtained by pressing or extraction. Spindle tree oil is soluble in halogenated hydrocarbons (chloroform, methylene chloride, etc.), acetone, alcohols, hydrocarbons (hexane, petroleum ether, etc.). The chemical composition of oil extracted by different solvents is different. In particular, chloroform and alcohols can extract cardiac glycosides that are toxic and the presence of which in the oil is undesirable. Therefore, we selected extraction with petroleum ether, which does not extract cardiac glycosides $[8,14,15]$.

Thus, obtained Spindle tree oil is lighter than water and has a refractive index similar to Sea buckthorn oil $(1,478)$. The basic numerical parameters are typical for semidrying fatty oils containing in their composition a high content of unsaturated fatty acids. This is evidenced by the elaidin test and the reaction with bromine water, which gave a positive result. 
From of the nine detected fatty acids (Table 2), 4 are unsaturated (oleic, palmitoleic, linoleic and linolenic), and they account for $87.79 \%$ of all fatty acids of Spindle tree.

Linoleic and linolenic acids are indispensable acids, and their absence causes mild stretch of the skin in rats, hair loss and poor healing of wounds. Linoleic acid is used in the biosynthesis of arachidonic acid, as well as some prostheglandins, leukotrienes and thromboxane [16].

At the same time, the wound healing effect of Sea buckthorn oil is to a large extent explained by the presence of high content of vitamins, first of all carotenoids (provitamin A) and tocopherols. Therefore, we have attempted to identify and quantify these two most important vitamins in the oil of Spindle tree (Euonymus europaea L.). For this purpose, the fatty oils were separated on a silica gel column and the fractions obtained were analyzed using TLC.

It was found that Spindle tree (Euonymus europaea L.) oil contains $26 \pm 5 \mathrm{mg}-\%$ carotenoids and $40 \pm 5 \mathrm{mg}-\%$ tocopherols. This is less than in Sea buckthorn oil 3.5-6 times, but much more than in most of the edible oils. According to the literature, such quantity carotenoids and tocopherols are sufficient for the manifestation of wound healing $[11,12]$.

The oil when injected orally did not cause death of animals. Symptoms of intoxication have not been revealed and the general condition of the animal, especially the behavior, character and coordination of movements, the response to external stimuli, the state of wool and mucous membranes has not changed for 14 days. Since such a high dose did not cause visible symptoms of poisoning, there was no need to study the toxicity of low doses of oil. Consequently, Spindle tree oil can be classified in the $4^{\text {th }}$ grade of danger in accordance with GOST 12.1.005-88

Sea buckthorn was chosen as drug for comparing because it exhibits a pronounced wound healing effect. Oil of Sea buckthorn is used mainly in the native form, possesses anti-inflammatory, epithelial, bactericidal, analgesic properties [11, 12].

According to the results obtained, on 10 days of application of turpentine all animals developed clear signs of inflammation. After its discontinuation in the control animals, visible signs of inflammation began to decrease, but on the $7^{\text {th }}$ day after the abolition were still noticeable. In animals that have been treated with Sea buckthorn oil, signs of inflammation such as swelling, redness, hemorrhages on day 4 of treatment completely disappeared, while in the treatment of Spindel tree oil currant, these symptoms disappeared later, 6-7 days of treatment (16-17 days of the experiment). In animals of the control group without treatment, the symptoms of dermatitis completely disappeared on the $10^{\text {th }}$ day after the removal of turpentine rubbing (the $20^{\text {th }}$ day of the experiment). This makes it possible to conclude that Spindle tree oil has a similar effect to Sea buckthorn oil, but it was a bit weaker by action, although it can also be used as a remedy for the treatment of skin diseases (Table 3).

Thus on the $5^{\text {th }}$ day of treatment with Sea buckthorn oil, the hematological parameters were normal, while in the treatment of Spindle tree oil, they still remained somewhat overestimated, although they were closer to normal than in the group of animals without treatment.

The study of biochemical parameters on the $15^{\text {th }}$ day of the experiment ( $5^{\text {th }}$ day of treatment) compared with the beginning of the abatement of the rubbing of the irritating factor $\left(10^{\text {th }}\right.$ day of the experiment) indicates an increase in the total protein. This increase has reached the norm in the application of Sea buckthorn oil and was slightly lower when using Spindle tree oil. The level of urea and beta-lipoproteins, which increases with inflammation, in the application of oil of Sea buckthorns and Spindle tree significantly decreased and on the $5^{\text {th }}$ day of treatment reached the norm for oil of Sea buckthorn and was close to that for Spindle tree oil.

Estimating the impact of Spindle tree oil and Sea buckthorn oil, it can be said that after 5 days of treatment, the animals experienced a marked therapeutic effect, accompanied by a decrease in the inflammatory process compared to control animals that were not treated or healing was naturally. However, Sea buckthorn oil had a more pronounced effect, possibly due to the higher content of carotenoids and tocopherols. At the same time, we confirmed the data of folk medicine on the wound healing effect of Spindle tree oil. Obtained by extraction with petroleum ether, it does not contain toxic substances and can be recommended for the treatment of skin diseases in the composition of ointments. 
This oil contains a large number of unsaturated fatty acids that can be easily oxidized, so when stored, it is necessary to reduce the contact with air oxygen, and in the manufacture of dosage forms to enter such prescriptions, where this contact will be minimal. It will help to extend the shelf life of medicines made on the basis of Spindle tree oil.

\section{Conclusions}

1. The content of fatty acids, carotenoids and tocopherols in Spindle tree (Euonymus europaea $L$.) oil, obtained by extraction with petroleum ether, was investigated. Found that 9 of the detected fatty acids, 4 are unsaturated (oleic, palmitoleic, linoleic and linolenic), and they together account for $87.79 \%$ of all fatty acids of Spindle tree oil. The resulting oil contains $26 \pm 5 \mathrm{mg}-\%$ carotinoids and $40 \pm 5 \mathrm{mg}-\%$ tocopherols. This is less than in Sea buckthorn oil 3.5-6 times, but much more than in most of the edible oils.

2. There were no symptoms of intoxication with the introduction of Spindle tree oil in the stomach of rats and it can be classified in the 4 the grade of danger in accordance with GOST 12.1.005-88.

3. On the model of non-allergic contact dermatitis, the anti-inflammatory activity of Spindle tree oil in comparison with oil of Sea buckthorn was investigated. It turned out to be less pronounced than in Sea buckthorn, but still high enough. Changes in the hematological and biochemical parameters in the studied animals (rats) were significantly better in the use of butter oil compared to those in untreated animals.

\section{References}

[1] Johansen, J. D., Aalto-Korte, K., Agner, T., Andersen, K. E., Bircher, A., Bruze, M. et. al. (2015). European Society of Contact Dermatitis guideline for diagnostic patch testing - recommendations on best practice. Contact Dermatitis, 73 (4), 195-221. doi: 10.1111/cod.12432

[2] Semenov, D. V. (2014). Study of Pharmacological Effect of Ointment with Aronia Oil of Blackheads. Ukrainian Biopharmaceutical Journal, 2, 31

[3] Konovalova, O. Yu., Tumanov, V. A., Mitchenko, F. A. et. al. (2011). Poisonous Plants. PE "Wandering MX", 494.

[4] Thomas, P. A., El-Barghathi, M., Polwart, A. (2010). Biological Flora of the British Isles: Euonymus europaeus L. Journal of Ecology, 99 (1), 345-365. doi: 10.1111/j.1365-2745.2010.01760.x

[5] Kumarasamy, Y., Cox, P. J., Jaspars, M., Nahar, L., Wilcock, C. C., Sarker, S. D. (2003). Biological activity of Euonymus europaeus. Fitoterapia, 74 (3), 305-307. doi: 10.1016/s0367-326x(03)00022-4

[6] Wanner, J., Tabanca, N., Zehl, M., Jirovetz, L., Schmidt, E., Patschka, A. et. al. (2015). Investigations into the Chemistry and Insecticidal Activity of Euonymus europaeus Seed Oil and Methanol Extract. Current Bioactive Compounds, 11 (1), 13-22. doi: 10.2174/157340721101150804142925

[7] Zhu, J.-X., Qin, J.-J., Chang, R.-J., Zeng, Q., Cheng, X.-R., Zhang, F. et. al. (2012). Chemical Constituents of Plants from the Genus Euonymus. Chemistry \& Biodiversity, 9 (6), 1055-1076. doi: 10.1002/ cbdv. 201100170

[8] State Pharmacopoeia of Ukraine (2001). Kharkiv: RIREG, 556.

[9] Grob, R. L., Barry, E. F. (2004). Modern Practice of Gas Chromatography. John Wiley \& Sons, 1064. doi: 10.1002/0471651141

[10] Sidorov, R. A., Zhukov, A. V., Pchelkin, V. P., Vereshchagin, A. G., Tsydendambaev, V. D. (2014). Content and Fatty Acid Composition of Neutral Acylglycerols in Euonymus Fruits. Journal of the American Oil Chemists' Society, 91 (5), 805-814. doi: 10.1007/s11746-014-2425-2

[11] Hernández-Ortega, M., Ortiz-Moreno, A., Hernández-Navarro, M. D., Chamorro-Cevallos, G., Dorantes-Alvarez, L., Necoechea-Mondragón, H. (2012). Antioxidant, Antinociceptive, and Anti-Inflammatory Effects of Carotenoids Extracted from Dried Pepper (Capsicum annuumL.). Journal of Biomedicine and Biotechnology, 2012, 1-10. doi: 10.1155/2012/524019

[12] Kumar, R., Kumar, G. P., Chaurasia, O., Bala Singh, S. (2011). Phytochemical and Pharmacological Profile of Seabuckthorn Oil: A Review. Research Journal of Medicinal Plant, 5 (5), 491-499. doi: 10.3923/ rjmp.2011.491.499 
[13] Mazurec, S. I., Kovalyov, S. V., Rudnyk, A. M. (2012). Phytochemical study of the lipophilic fraction from the leaves of ordinary hops. Zaporizhzhia Medical Journal, 72 (3), 96-99.

[14] Marchyshyn, S., Krasulya, N., Kulitska, M., Ostrovska, G. (2011). Investigation of the lipophilic fraction of the herb of the chammeria narrow-gauge. Farmacevtuchnyj chasopys, 1, 18-21.

[15] Sidorov, R. A. (2013). Composition of greasy oils of berry bushes fruits. Moscow, 22.

[16] Pharmaceutical Encyclopedia (2010). Kyiv: MORION, 1632

[17] Poddubny, N. P., Sampiyev, A. M. (2000). Beta-carotene: experience and perspectives in medicine. Krasnodar, 34.

[18] Yakovleva, L. V., Tkachova, O. V., Gladuk, E. V. (2003). Study of the therapeutic effect of the almond ointment on the model of contact turpentine dermatitis in rats. Collection of scientific works of NMAPO named after P. L. Shupyk, 12 (1), 1000-1005.

[19] Happe, M. R., Battafarano, D. F., Dooley, D. P., Rennie, T. A., Murphy, F. T., Casey, T. J., Ward, J. A. (2002). Validation of the Diesse Mini-Ves Erythrocyte Sedimentation Rate (ESR) Analyzer Using the Westergren ESR Method in Patients With Systemic Inflammatory Conditions. American Journal of Clinical Pathology, 118 (1), 14-17. doi: 10.1309/yhyl-8xth-5jm2-43ej

[20] Kamyshnikov, B. C. (2009). Reference book for clinical and biochemical research and laboratory diagnostics. MED press-inform, 920 .

\title{
PARANOID SCHIZOPHRENIA NEGATIVE SYMPTOMS FEATURES IN CASE OF PRESENCE OF MUSICAL EAR
}

\author{
Natalya Kostyuchenko \\ Department of Psychiatry and Psychotherapy \\ Danylo Halytsky Lviv National Medical University \\ 69 Pekarskaya str., Lviv, Ukraine, 79010 \\ n.kostyuchenko@gmail.com \\ Olexander Filts \\ Department of Psychiatry and Psychotherapy \\ Danylo Halytsky Lviv National Medical University \\ 69 Pekarskaya str., Lviv, Ukraine, 79010 \\ filz_uuap@mail.lviv.ua
}

\begin{abstract}
In our work, we propose one of the options for a prognostic criterion, which at the beginning of the disease can provide sufficient evidence to predict the form and severity of negative symptoms in schizophrenia.

Aim. To investigate the influence of the presence of ear on music on the degree of severity of deficiency symptoms in paranoid schizophrenia.

The study was conducted on the basis of the third clinical department of the Lviv Regional Clinical Psychiatric Hospital for the period of 2015. 40 patients with paranoid form of schizophrenia, aged 18 to 35, were examined, of which: group I - 20 patients with advanced ear on music (average age $28.60 \pm 1.01$ years) and group II -20 patients with no ear on music (average age $27.30 \pm$ \pm 1.15 years). The main methods of studying the observation groups were: clinical-psychopathological, pathopsychological, and statistical. The pathopsychological study of the evaluation of negative symptoms was conducted using the "Qualitative Assessment Scale for Positivity, Negative and General Psychopathological Syndromes” (PANSS - Positive and Negative Syndrome Scale), namely, its PANSS-NS subscale. Comparison of the probability of the difference between the average indices of unrelated groups was carried out using the Mann-Whitney method, comparing the relative parameters of the distribution structure by the xi-square criterion.

Analysis of the results of the study shows that in patients with developed ear on music, the level of deficiency symptoms of negative symptoms under the PANSS-NS subclass is 2.2 times lower $(p<0.01)$ than in patients with no developed ear on music: $2.04 \pm 0.14$ against $4.46 \pm 0.17$ points, respectively. Comparing the key indicators of the PANSS-NS subscale in patients with paranoid schizophrenia with advanced ear on music, it was found that the manifestations of "Violations of abstract thinking" (N5 - 2.35 \pm \pm 0.15 points), "Violation of spontaneity and smoothness in the conversation" (N6 - $2.30 \pm 0.15$ points) and "Stereotyped thinking"
\end{abstract}

